\title{
Laboratory measurements of low- and high-frequency elastic moduli in Fontainebleau sandstone
}

\author{
Emmanuel C. David ${ }^{1}$, Jérome Fortin ${ }^{2}$, Alexandre Schubnel ${ }^{2}$, Yves Guéguen², \\ and Robert W. Zimmerman ${ }^{3}$
}

\begin{abstract}
The presence of pores and cracks in rocks causes the fluid-saturated wave velocities in rocks to be dependent on frequency. New measurements of the bulk modulus at low frequencies $(0.02-0.1 \mathrm{~Hz})$ were obtained in the laboratory using oscillation tests carried out on two hydrostatically stressed Fontainebleau sandstone samples, in conjunction with ultrasonic velocities and static measurements, under a range of differential pressures (10-95 MPa), and with three different pore fluids (argon, glycerin, and water). For the $13 \%$ and $4 \%$ porosity samples, under glycerin- and watersaturated conditions, the low-frequency bulk modulus at $0.02 \mathrm{~Hz}$ matched well the low-frequency and ultrasonic dry bulk modulus. The glycerin- and water-saturated samples were much more compliant at low frequencies than at high frequencies. The measured bulk moduli of the tested rocks at low frequencies $(0.02-0.1 \mathrm{~Hz})$ were much lower than the values predicted by the Gassmann equation. The frequency dispersion of the $\mathrm{P}$ and $\mathrm{S}$ velocities was much higher at low differential pressures than at high pressures, due to the presence of open cracks at low differential pressures.
\end{abstract}

\section{INTRODUCTION}

Measurements of elastic wave velocities represent a powerful diagnostic tool for the microstructure and fluid content of rocks. However, because wave velocities in fluid-saturated rocks are frequency dependent, the elastic behavior observed in the laboratory at "high-frequencies" ( $\sim \mathrm{MHz})$ does not, in general, hold at intermedi- ate to low frequencies, such as those used in the field (typically: $1-10 \mathrm{kHz}$ for sonic logging, $10-100 \mathrm{~Hz}$ for reservoir monitoring) or which are of interest in seismology (typically around $1 \mathrm{~Hz}$ or less). Three main frequency regimes can, indeed, be defined, depending on the ability of the fluid to move from pore to pore at the passing of a wave (O'Connell and Budiansky, 1977; Cleary, 1978). The stiffest elastic behavior is expected at high frequencies, where the fluid present in the pores behaves as if the pores were totally isolated or, in different terms, as if they were individually undrained with regard to fluid flow. It is generally thought that such a situation occurs at the passing of an ultrasonic wave in the laboratory (Dvorkin et al., 1995). An intermediate situation, in which pores are connected and in local pore pressure equilibrium (i.e., at the representative elementary volume [REV] scale), corresponds to the undrained behavior in the sense of poroelasticity, following the Gassmann model. The most compliant elastic behavior is expected to occur at very low frequencies, where pore pressures have sufficient time to fully equilibrate at a macroscopic scale (i.e., at a scale large compared to the REV scale) and are, therefore, not affected by the seismic wave. It is recalled that, as the theory of poroelasticity ignores chemical interactions between the fluid and the grains, in such a drained regime, the rock should behave as if it was dry. No velocity dispersion is therefore expected for dry rocks.

Current understanding of the frequency-dependence of wave velocities in saturated rocks is limited by a lack of laboratory data at low frequencies. Sams et al. (1997) obtain measurements of seismic velocities, as well as attenuation, using a combination of vertical seismic profiles, crosshole seismic, sonic logs, and ultrasonic measurements from four boreholes, but their techniques use different amplitudes, resolutions, and scales that make a direct comparison difficult. Most laboratory measurements have traditionally been limited to static (zero-frequency) and ultrasonic (high-frequency) measurements. Between these two frequencies, experimental data

Manuscript received by the Editor 23 February 2013; revised manuscript received 16 May 2013; published online 10 September 2013.

${ }^{1}$ Formerly (at the time of the research) Imperial College, Department of Earth Science and Engineering, London, UK; presently Australian National University, Research School of Earth Sciences, Canberra, Australia. E-mail: emmanuel.david08@imperial.ac.uk.

${ }^{2}$ École Normale Supérieure, Laboratoire de Géologie, Paris, France. E-mail: jerome.fortin@ens.fr; aschubnel@biotite.ens.fr; yves.gueguen@ens.fr.

${ }^{3}$ Imperial College, Department of Earth Science and Engineering, London, UK. E-mail: r.w.zimmerman@imperial.ac.uk.

(C) 2013 Society of Exploration Geophysicists. All rights reserved. 
are difficult to obtain. A comprehensive review of the available laboratory techniques for measuring wave velocities and attenuation is given by Bourbié et al. (1987) and, more recently, by Batzle et al. (2006).

The stress-strain method is one such technique that has recently been the subject of much experimental effort. Rock samples, placed in a triaxial apparatus, are subjected to forced oscillations. Elastic moduli and attenuation, as a function of frequency, are extracted from the ratio and the phase shift, respectively, of the measured stress and strain. The stress-strain technique requires vibrating systems and sensitive displacement (or strain) transducers and making the measurements at low strain to avoid non-linear elastic effects as caused by crack closure and reopening. The first such attempts seem to have been made by Spencer (1981), who measures the complex Young's modulus over the range 4 to $400 \mathrm{~Hz}$ on various rock samples (vacuum dry and saturated with various fluids). However, electrochemical interactions between the pore fluid and the solid grains, which are out of the scope of the present work, were shown to account for most of the frequency-dependence of velocities on the Navajo sandstone sample. Measurements of the shear modulus and attenuation on calcite are obtained under pressure (25$300 \mathrm{MPa}$ ) by Jackson and Paterson (1987), over the range 0.01-0.3 Hz, using torsional oscillations. Nevertheless, it is difficult to clearly interpret their results in the present context of pressure ranges in which rocks are far from conditions of grain crushing and pore collapse. Currently, their equipment is being modified to allow for torsional and flexural oscillation measurements (Jackson et al., 2011). A complete set of elastic moduli (Young's modulus and Poisson's ratio) is measured on a dry and glycerin-saturated sandstone by Batzle et al. (2001, 2006), at low effective pressures ( 7 to $17 \mathrm{MPa}$ ), over the range 5 to $2500 \mathrm{~Hz}$. Ultrasonic velocities were also measured on the same sample, and compared with the velocities calculated from measurements of Young's modulus and Poisson's ratio at lower frequencies. Similar measurements are obtained by Adam et al. (2006) and Adam and Batzle (2008) on dry and brine-saturated carbonates, at $100 \mathrm{~Hz}$, under pressure (0-30 MPa). The results of Batzle et al. (2006) show a clear increase of compressional and shear velocities with frequency, for saturated samples, in the seismic frequency range (consistent with the attenuation values). The highest saturated velocities were measured at ultrasonic frequencies, whereas the dry velocities remained almost unchanged with frequency, as expected. Low-frequency measurements for the bulk modulus $(0.01-0.1 \mathrm{~Hz})$ are obtained by Adelinet et al. (2010) on a dry and water-saturated Icelandic basalt, over the pressure range 0-190 MPa. Simultaneous measurements of ultrasonic velocities were taken. Their results show that the lowfrequency saturated bulk modulus, which was assumed to be the drained modulus, is significantly lower than the high-frequency saturated bulk modulus. However, there was a non-negligible mismatch between the low-frequency dry moduli, the high-frequency dry moduli, and the saturated drained moduli, which should, in principle, be equal to each other.

Most past attempts to measure low-frequency wave velocities in the laboratory have only determined one elastic modulus, have been limited to a narrow frequency range, or have only used one pore fluid. The need also arises for more measurements under pressure because it is well known that velocity dispersion is highly dependent on the presence of open cracks in rocks (Winkler, 1986). The main objective of the experimental work reported in the present paper is to measure the bulk modulus at low frequencies, under pressure, and using different pore fluids, in a particular sandstone: Fontainebleau sandstone. A series of experiments was carried out on two hydrostatically stressed samples, having porosities of $13 \%$ and $4 \%$, using a triaxial apparatus. The samples were successively saturated with argon, glycerin, and water, maintained at a constant pore pressure of $5 \mathrm{MPa}$. Rock strain, ultrasonic P- and S-velocities ( $1 \mathrm{MHz}$ ), and permeability were recorded as functions of hydrostatic pressure (up to $95 \mathrm{MPa}$ ), as well as low-frequency values for the bulk modulus $(0.02-0.1 \mathrm{~Hz})$, which were obtained by small oscillations of the confining pressure, using a hydraulic pump, following the method already tested by Adelinet et al. (2010). Strain gauges, directly glued on the sample, were used for strain measurements. The comparison of these new low-frequency data for the bulk modulus with ultrasonic data allows for an estimation of the amount of velocity dispersion with frequency.

\section{EXPERIMENTAL SETUP AND METHODS}

\section{Sample description and preparation}

Fontainebleau sandstone is an Oligocene arenite found in the region of Île-de-France near Paris, formed of pure quartz grains that are well sorted and have a nearly uniform grain size of around $250 \mu \mathrm{m}$ (Bourbié et al., 1987). It is purely isotropic and presents an exceptionally wide variation of porosities, ranging between $2 \%$ and $30 \%$. Fontainebleau sandstone also has the advantage of having been widely studied, e.g., for mechanical properties (Bourbié and Zinszner, 1985; Song and Renner, 2008) as well as transport properties (Bourbié and Zinszner, 1985; Fredrich et al., 1993; Song and Renner, 2008; Dautriat et al., 2009). Thin sections, micrographs, and pore structure characterization of Fontainebleau sandstone can be found, for example, in Bourbié et al. (1987), David et al. (1993), Fredrich et al. (1993), and Song and Renner (2008).

Two cylindrical specimens of Fontainebleau sandstone, of $40 \mathrm{~mm}$ in diameter and length, were, respectively, cored from two blocks of Fontainebleau sandstone, having porosities of approximately $13 \%$ and $4 \%$, and rectified to ensure perfect parallelism of the two ends surfaces, with a precision of $\pm 10 \mu \mathrm{m}$. The $4 \%$ porosity specimen was then heat treated at a temperature of $500^{\circ} \mathrm{C}$ for $24 \mathrm{~h}$, after which it was directly cooled to room temperature. Such a procedure is well known to induce thermal cracking (Darot et al., 1992).

The physical properties of the two Fontainebleau sandstone specimens are summarized in Table 1. Porosities and grain and bulk densities were obtained using the water saturation triple weight method. This method, which consists in jointly measuring the weight of an oven-dry sample, a water-impregnated sample, and a water-immersed sample, has the advantage of being independent of grain density or sample volume measurements. Evidence of the accuracy of this method can be found when observing the obtained values for the grain densities for the two samples (Table 1), which are both extremely close to the common value of quartz density $\left(2650 \mathrm{~kg} / \mathrm{m}^{3}\right)$ given by Mavko et al. (2009), as expected. Grain density and porosity measured by triple weighting before heat treatment, on a sample cored from the same block as the heat-treated $4 \%$ sample, were $2642 \mathrm{~kg} / \mathrm{m}^{3}$ and 0.038 , respectively. Water permeabilities were measured in the triaxial apparatus during the water-saturated pressurization cycle, using the pore pressure volumetric pumps. The values given in Table 1 were taken at a confining pressure of $P_{c}=10 \mathrm{MPa}$, and a pore pressure of $P_{p}=5 \mathrm{MPa}$. 
Zero-pressure permeabilities of the two samples were not measured but should be close to the values given in Table 1 because the permeabilities of both samples were found to be nearly independent of pressure. Moreover, the values given in Table 1 are consistent with the porositypermeability relations for Fontainebleau sandstone found by Bourbié and Zinszner (1985) over a wide range of porosities. The initial (open air) velocities given in Table 1 were measured at room temperature, on the oven-dried samples, using two pairs of ultrasonic SOFRANEL P- and S-wave transducers.

Pore size distributions were obtained using a mercury porosimeter (AutoPore IV 9500 V1.07 Micromeritics Instrumentation). Such values are model-dependent because the pore entry radius is derived from the intrusion pressure using Jurin's formula, which is implicitly based on the assumption that the pore medium is formed of a collection of cylindrical tubes having different radii. Thus, the obtained pore size distributions, which are shown in Figure $1 \mathrm{~b}$ for the two Fontainebleau sandstone samples, should rather be seen as a pore threshold distribution (Dullien, 1992). The values of mean pore entry diameter increase from $7 \mu \mathrm{m}$ for the $4 \%$ porosity sample to $30 \mu \mathrm{m}$ for the $13 \%$ porosity sample and are consistent with the trends and values of the mercury porosimetry diagrams that Bourbié and Zinszner (1985) obtain, although the $4 \%$ sample has the distinction of having undergone thermal treatment. Nevertheless, it is likely that the effect of such treatment is not to modify the main pore entry diameter, but rather to create a population of thermal cracks having much smaller pore entry diameters. The observed bimodal character of the pore size distribution for the $4 \%$ sample supports this interpretation. The lowest value of the entry diameter is approximately $0.4 \mu \mathrm{m}$. For comparison, pore size distributions were also obtained on a $4 \%$ sample that was not heat treated, and no peak was observed at a pore entry diameter of $0.4 \mu \mathrm{m}$.

Strain gauges were directly glued onto the sample surface, after a layer of epoxy glue was first applied and then polished to form a perfectly smooth surface. The sample was then oven dried at $40^{\circ} \mathrm{C}$ for several days prior to the experiment and jacketed in a perforated neoprene sleeve. Finally, four piezoelectric transducers (PZTs) were glued onto the sample surface, after which the assembly (Figure 2) was placed in the triaxial apparatus.

\section{Apparatus}

Hydrostatic deformation experiments were conducted in an oil medium triaxial apparatus, the diagrams and descriptions of which can be found in Fortin et al. (2005, 2007). The confining pressure is applied by a servocontrolled volumetric pump and is measured by a pressure transducer with an accuracy of approximately $0.05 \mathrm{MPa}$. Thirty-four electrical wire outputs allow for simultaneous measurements of strain and ultrasonic velocities during the tests.

An internal pore pressure can be varied independently of the external confining pressure by a pair of connected Quizix volumetric servopumps, which can be controlled with respect to either pressure, flow, or volume. The accuracies of the pore pressure and pore volume measurements are $0.001 \mathrm{MPa}$ and $0.1 \mu \mathrm{l}$, respectively.
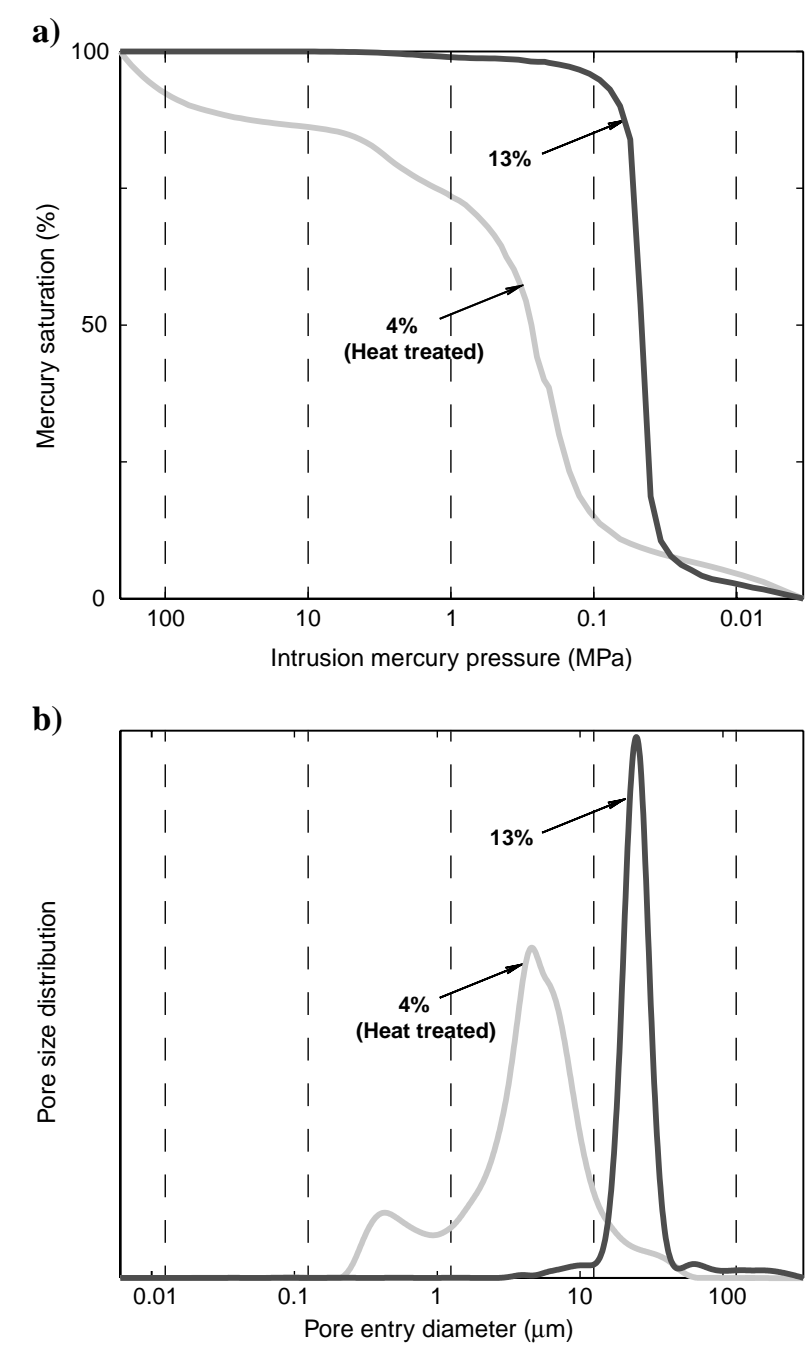

Figure 1. (a) Cumulative mercury intrusion volume as a function of mercury intrusion pressure, for the $13 \%$ and the heat-treated $4 \%$ porosity Fontainebleau sandstone samples (experimental data). (b) Pore size distributions, obtained using the derivative of saturation with respect to logarithmic pressure (rather than linear pressure), so as to characterize the presence of a double porosity (see Lenormand, 2003). The data were smoothed using a spline function. For the $4 \%$ sample, unrealistic non-zero values of the distribution function at very low and very large pore diameters $(0.01$ and $200 \mu \mathrm{m}$ ) were removed prior to data smoothing. 


\section{Strain measurements}

Samples were equipped with one pair of axial and circumferential strain gauges (Tokyo Sokki TML QFCB). The volumetric strain $\varepsilon_{v}$ was calculated from the measured axial and radial strains, which are denoted by $\varepsilon_{\mathrm{ax}}$ and $\varepsilon_{\mathrm{rad}}$, respectively, as $\varepsilon_{v}=\varepsilon_{\mathrm{ax}}+2 \varepsilon_{\mathrm{rad}}$. The accuracy of such local strain measurements is close to the microstrain. Each $120 \Omega$ strain gauge was mounted on a precision one-fourth Wheatstone bridge. Strain data could be recorded up to a frequency of $2400 \mathrm{~Hz}$.

\section{Ultrasonic velocity measurements}

Active ultrasonic velocity surveys were performed using four ultrasonic radial PZTs (lead-zircon-titanium) (one pair of P-wave transducers and one pair of S-wave transducers). A detailed description of such transducers can be found in Brantut et al. (2011) and Ougier-Simonin et al. (2011).

A $250-\mathrm{V}$ pulse was successively applied in each of the four sensors (at an initial time that is known), at its central resonant frequency of $1 \mathrm{MHz}$ (rise time of $1 \mu \mathrm{s}$ ), while the received waveforms were recorded by the other sensors (at a sampling frequency of $50 \mathrm{MHz}$ ). The following data processing procedure is similar to the one detailed in Brantut et al. (2011). For each survey, two P-wave arrival times and two S-wave arrival times were automatically picked using InSite software (ASC Ltd.). In the cases of the few events for which automatic picking was not successful, arrival times were picked manually. Waveforms were then crosscorrelated with reference to a "master survey" (i.e., the best quality survey), which was chosen to be survey recorded at the highest hydrostatic pressure in the experiments (95 MPa). The crosscorrelation procedure is well known to significantly reduce the relative errors of arrival time picking during successive velocity surveys.

To obtain the true time of flight $\bar{t}$ along the rock sample diameter, the total time of flight $t_{t}$ obtained after crosscorrelations, was systematically corrected for the time of flight $t_{0}$ in the metal-support pieces of the two wave transducers. Thus, $\bar{t}=t_{\mathrm{t}}-t_{0}$. The time of flight $t_{0}$ is distinct for $\mathrm{P}$ - and S-wave pairs of sensors. For a given pair of sensors, $t_{0}$ was determined by comparing the measured times of flight obtained using a pair of given sensors and a pair of SOFRANEL transducers (for which $t_{0}$ is known), along the radius of an aluminum standard cylinder. An aluminum standard was
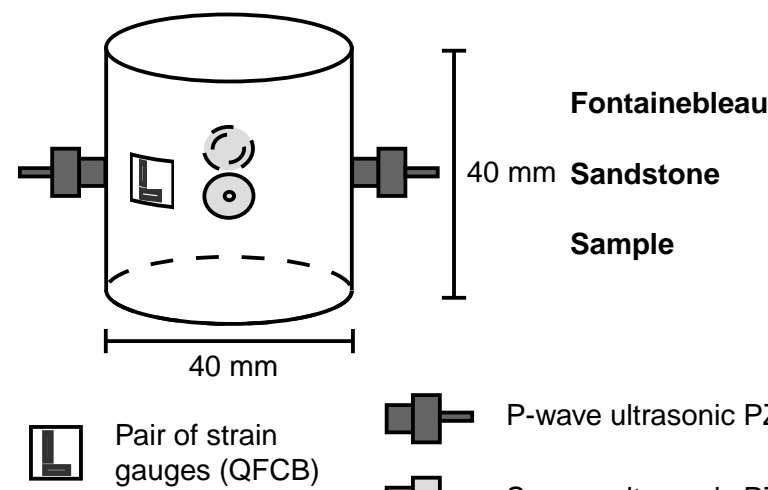

Pair of strain gauges (QFCB)

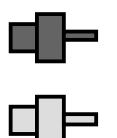

P-wave ultrasonic PZT

S-wave ultrasonic PZT

Figure 2. Sample assembly for the two Fontainebleau sandstone specimens tested. The sample was jacketed in a neoprene sleeve (n.b., not represented here). preferred for such measurements, rather than the rock sample, because of the much higher quality of the waveforms.

The true sample diameter $d$ at each hydrostatic pressure stage was obtained by correcting the initial sample diameter $d_{i}$ from the strain data, i.e., $d=d_{i}\left(1-\varepsilon_{\text {rad }}\right)$. Average velocities $\bar{V}$ along the sample diameter were then directly given by $\bar{V}=d / \bar{t}$. The relative error between successive velocities measurements (after crosscorrelation) is less than $0.5 \%$. Absolute velocity values are estimated to be obtained with less than $2 \%$ error.

\section{Low-frequency bulk modulus measurements}

The pressure control software (Falcon ST, Inc.) allows forced oscillations of the confining pressure so that the low-frequency bulk modulus could be obtained from the measured volumetric strains during such tests. Small oscillations of the confining pressure are superimposed on the background existing confining pressure.

The forced oscillation system is limited to a maximum frequency of around $0.5 \mathrm{~Hz}$ because smaller amplitudes are required as the frequency increases. During the experiments, the amplitudes required for frequencies higher than $0.1 \mathrm{~Hz}$ were too small to be accurately measured by the pressure transducer and the strain gauges. Therefore, bulk modulus measurements were obtained at frequencies of $f=0.02 \mathrm{~Hz}, f=0.05 \mathrm{~Hz}$, and $f=0.1 \mathrm{~Hz}$. The amplitude of the recorded axial strain is typically around $10^{-5}$ when the pump oscillation volume $\Delta V$ is equal to $2 \mathrm{~cm}^{3}$ (as for measurements carried at frequency $f=0.02 \mathrm{~Hz}$ ); $\varepsilon_{\mathrm{ax}} \sim 5 \times 10^{-6}$ when $\Delta V=1 \mathrm{~cm}^{3}$ (as for frequencies $f=0.02 \mathrm{~Hz}$ and $f=0.05 \mathrm{~Hz}$ ); values of $\varepsilon_{\mathrm{ax}}$ as low as $2 \times 10^{-6}$ were satisfactorily recorded when $\Delta V=0.5 \mathrm{~cm}^{3}$ (as for frequencies $f=0.02 \mathrm{~Hz}$ and $f=0.1 \mathrm{~Hz}$ ). Note that Winkler et al. (1979) and Nur and Murphy (1981) measure wave velocities on sandstones in extension and shear, respectively, at small strain amplitudes in the range from $10^{-7}$ to $10^{-5}$, using the resonant bar technique. They concluded that wave velocities remain independent of strain, as long as strain is lower than $10^{-6}$.

The procedure for obtaining the bulk modulus, which is illustrated on one example in Figure 3, is as follows: Measurements of confining pressure and volumetric strain were taken over a large number of oscillation cycles (at least twenty cycles). Stress-strain measurements were then divided into individual cycles, and only the cycles for which the strain gauge signal was of acceptable quality (strain gauge data were often affected by drifts and sudden jumps) were manually selected. The bulk modulus was calculated in the stress-strain space during loading and unloading portions of each individual cycle, to verify the absence of non-linearity caused by crack closure and opening. Finally, the bulk modulus is calculated as the median of bulk moduli calculated for individual cycles. The median absolute deviation gives the error.

Although a condition of constant pore pressure $\left(P_{p}=5 \mathrm{MPa}\right)$ was imposed while the confining pressure was oscillating, it is not necessarily implied that the sample behaves as fully drained during such tests. As the pore space deforms during oscillations, pore fluid will squish in and out of the sample ends, resulting in pore pressure changes in the pore fluid circuit that are readjusted as rapidly as allowed by the servocontrolled pump. However, if the frequency of the vibration is sufficiently high, pore pressure gradients may exist locally in the rock sample, regardless of whether a constant pore pressure is imposed (and measured) at both sample ends. It would be difficult to identify a frequency-dependent pore fluid relaxation mechanism in the rock sample if undrained conditions 
were externally imposed by stopping the pore pressure pumps or closing the pore circuit using a valve as close as possible to the sample, which is the other possibility. In that case, true undrained conditions would not really apply, because the sample would still not be sealed at both ends. The amount of fluid contained in the portion of pore circuit pipes located between the sample and the closed valve would not be negligible. Moreover, according to the configuration of the pore pressure system, no pore pressure measurements would then be available because they are taken far apart at the pump cylinder entry. Hence, although the question of what pore pressure condition should be externally imposed remains unresolved, the second possibility was excluded.

\section{Procedure}

A series of three drained hydrostatic cycles (argon-, glycerin-, and then water-saturated) were carried out on each Fontainebleau sandstone jacketed specimen, up to a hydrostatic pressure of $95 \mathrm{MPa}$ and at the same constant pore pressure of $5 \mathrm{MPa}$. The physical properties of the three pore fluids are summarized in Table 2.

The first hydrostatic cycle, in which samples are saturated with argon gas, is completely equivalent to a dry cycle. Because samples were oven dried but not vacuum dried, they may still have contained a very small amount of pore fluid during the dry cycle. It is well known that the influence of moisture on acoustic properties is significant in sandstones (Murphy, 1982; King and Marsden, 2002), although Fontainebleau sandstone has the advantage of being completely clay free. However, chemical interactions were not considered in the present study. It is believed that such effects remain relatively independent of pressure, and they are of minor influence compared to the micromechanical static closure of cracks, as well as viscoelastic effects due to motion of the pore fluid induced by the passing of a wave.

In addition to water, glycerin was also selected as a pore fluid, for theoretical and technical reasons. The effect of the wave frequency on wave velocities, which is related to the ability of the pore fluid to move within the pore space, is strongly dependent on the fluid viscosity (O'Connell and Budiansky, 1977; Jones and Nur, 1983). Because the viscosity of glycerin is three orders of magnitude higher than that of water, it is expected that the chance of observing different frequency regimes is greater if both glycerin and water are successively used as pore fluids. Moreover, glycerin can be rinsed by water, and so the same sample can be used in the series of hydrostatic cycles. It should be noted that after such a rinsing procedure (see the next paragraph), the water will still contain a small concentration of glycerin. The reason why glycerin was then used second, and water third, and not in the opposite order, is that the viscosity of a solution of pure glycerin decreases drastically with the addition of even a very small amount of water, whereas the viscosity of water remains unchanged with the addition of non-negligible concentrations of glycerin.

During each hydrostatic cycle, hydrostatic pressure was first increased to $10 \mathrm{MPa}$. Pore fluid saturation was then initiated from the bottom of the sample only, the top pore fluid inlet being connected to the pore pressure pump only after the pore fluid came out of it. Pore pressure was raised to $5 \mathrm{MPa}$ and held constant for at least $12 \mathrm{~h}$ to ensure complete saturation of the pore space. Hydrostatic pressure was then increased in steps of $5 \mathrm{MPa}$, at a controlled rate of $0.01 \mathrm{MPa} / \mathrm{s}$, and kept constant after the hydrostatic pressure plateau was reached for at least $15 \mathrm{~min}$, so as to ensure a complete "relaxation" (Fortin et al., 2007) (relaxation of the viscoelastic type, e.g., fluid drainage, as well as grain and pore space deformation). During each step of the hydrostatic loading, including the initial step (at $P_{c}=10 \mathrm{MPa}$ and $P_{p}=5 \mathrm{MPa}$ ), ultrasonic velocities, low-frequency bulk modulus, and permeability (only glycerin and water permeability) were successively measured following the methods described in previous sections. The maximum hydrostatic pressure was $95 \mathrm{MPa}$, which should be sufficient to close all cracks. Samples were unloaded at a constant stress rate of $0.03 \mathrm{MPa} / \mathrm{s}$. Rock strain was continuously recorded during loading and unloading phases.
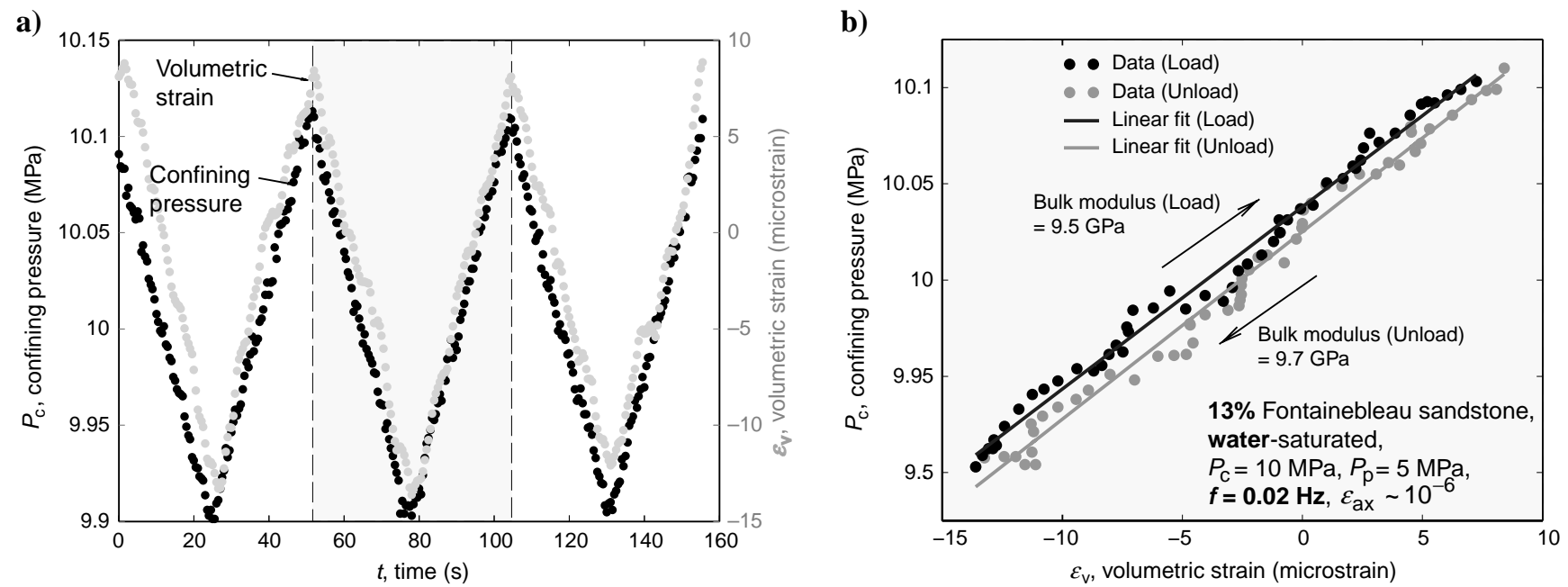

Figure 3. Example of experimental data during oscillations of the confining pressure $\left(f=0.02 \mathrm{~Hz}, \varepsilon_{\mathrm{ax}} \sim 10^{-5}\right)$ for measuring bulk modulus, on the water-saturated $13 \%$ porosity Fontainebleau sandstone $\left(P_{c}=10 \mathrm{MPa}, P_{p}=5 \mathrm{MPa}\right)$. (a) Confining pressure and volumetric strain as functions of time, for three oscillation cycles. (b) Data for the second cycle of (a) in the corresponding stress-strain curve, showing linear fits of the loading and unloading phases of the oscillation cycle. 


\section{RESULTS}

\section{Mechanical data}

The static hydrostatic pressure-volumetric strain behavior remains similar during the three successive hydrostatic cycles, for the $13 \%$ Fontainebleau sandstone sample (Figure 4a) and the $4 \%$ Fontainebleau sandstone sample (Figure 4b), with negligible hysteresis. This is consistent with the theoretical understanding that hysteresis, which does occur under deviatoric loading, is due to shear displacement along closed crack faces (David et al., 2012). According to this model, hysteresis would not be expected to occur under hydrostatic loading. The significant drift observed for the $4 \%$ porosity sample during the loading phase of the dry cycle is probably an artifact, related to the first application of hydrostatic pressure, because this is no longer observed during unloading and during the two subsequent hydrostatic cycles. The pressure dependence of the tangent static bulk modulus, which is the local slope of the stress-strain curve, is consistent with the behavior of the bulk modulus that is observed in the dry ultrasonic velocity data. It can be assumed that any deviation from linear elastic behavior is directly related to crack closure (Zimmerman et al., 1986). Therefore, the "initial" crack porosity (at a differential pressure, $\left.P_{c}-P_{p}=5 \mathrm{MPa}\right)$ can be estimated if the linear portion of the

Table 2. Physical properties of the pore fluids used in the experiments. Values are given at a pressure of $5 \mathrm{MPa}$ and at room temperature $\left(20^{\circ} \mathrm{C}\right)$, after Landolt and Börnstein (1982).

\begin{tabular}{lrcc}
\hline Pore fluid & $\begin{array}{r}\text { Density } \\
\left(\mathrm{kg} / \mathrm{m}^{3}\right)\end{array}$ & $\begin{array}{c}\text { Bulk modulus } \\
(\mathrm{GPa})\end{array}$ & $\begin{array}{c}\text { Viscosity } \\
(\text { Pa.s })\end{array}$ \\
\hline Argon (gas) & 83 & 0.005 & $2.4 \times 10^{-5}$ \\
Glycerin & 1262 & 4.36 & 1.08 \\
Water & 999 & 2.25 & $0.89 \times 10^{-3}$ \\
\hline
\end{tabular}

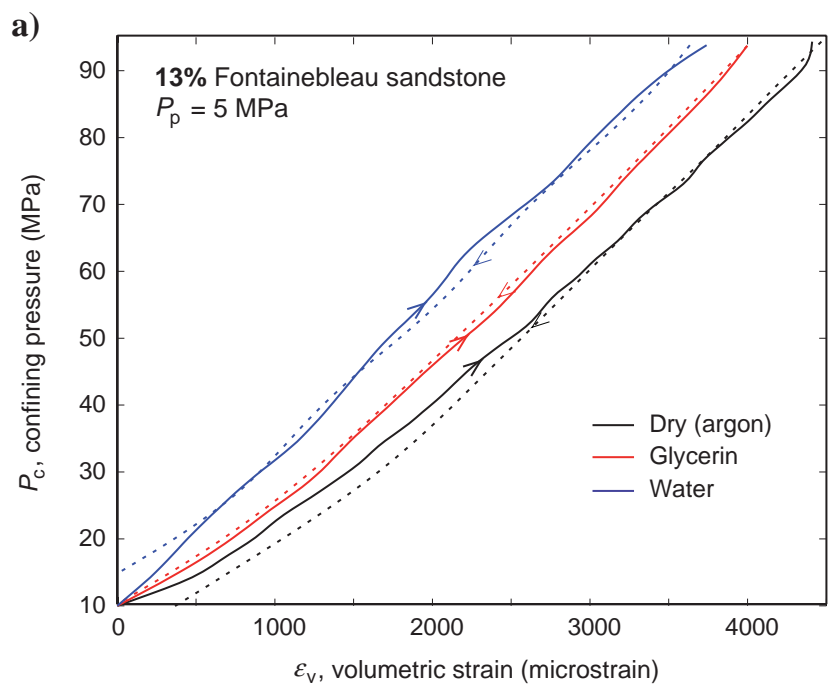

stress-strain curve, as observed at high pressures (whose slope then represents the static bulk modulus of the "matrix" formed by the minerals and the non-closable pores), is extended to intersect the strain axis. Thus, for the $13 \%$ and $4 \%$ samples, crack porosity is estimated to be $0.06 \%$ (using the glycerin-saturated cycle data) and $0.01 \%$ (using the water-saturated cycle data), respectively.

\section{Ultrasonic velocity data}

Similar pressure and pore fluid dependences are observed for Pand S-wave ultrasonic velocity measurements, on the $13 \%$ porosity specimen (Figure 5a, 5c) and the $4 \%$ porosity specimen (Figure $5 \mathrm{~b}$, $5 \mathrm{~d}$ ), except that the P- and S-velocities take substantially higher values in the less porous $4 \%$ sandstone, as expected. Experimental values for P- and S-velocities are consistent with previously published values on Fontainebleau sandstone samples having similar porosities (see Bourbié and Zinszner, 1985; Song and Renner, 2008). Note that no hysteresis was observed on the velocities (although this is not shown in Figure 5), as was also the case for static deformation. Both data sets confirm that cracks reopen during depressurization.

The P- and S-wave velocities increase with pressure, as cracks gradually close. Because the increase of $\mathrm{P}$ - and $\mathrm{S}$-wave velocities is more significant for the $13 \%$ porosity sample than for the heattreated $4 \%$ porosity sample, it is therefore likely that the $13 \%$ porosity sample naturally contains numerous cracks, although the population of cracks could not be clearly identified in the pore size distribution (Figure 1b). P- and S-wave velocities reach a plateau at high pressures, where the values attained must reflect only the influence of the non-closable pores. Both $V_{\mathrm{P}}$ and $V_{\mathrm{S}}$ are very sensitive to changes in the pore fluid bulk modulus (see Table 2) (David and Zimmerman, 2012). When the bulk modulus of the pore fluid increases, $V_{\mathrm{P}}$ takes on higher values, but less pressure dependence is observed. In contrast, an increase in the pore fluid bulk modulus causes $V_{\mathrm{S}}$ to take higher values only at low pressures: A "crossing point" is clearly observed at intermediate pressures (around 20$30 \mathrm{MPa}$ for both sandstones), after which saturated shear velocities

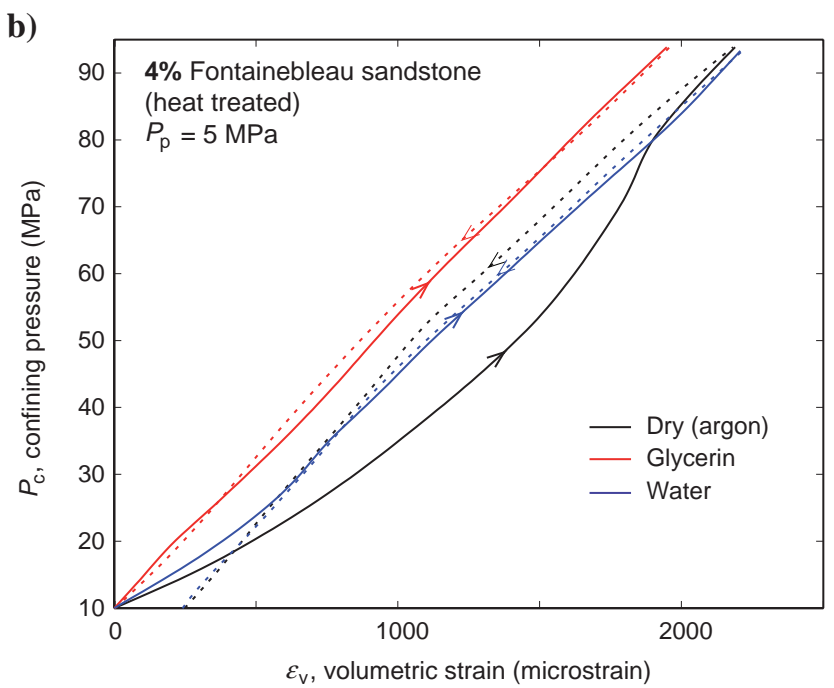

Figure 4. Volumetric strain as a function of confining pressure, for the three complete hydrostatic cycles. Volumetric strain was calculated as $\varepsilon_{v}=\varepsilon_{\mathrm{ax}}+2 \varepsilon_{\mathrm{rad}}$, using the pair of strain gauges. (a) The $13 \%$ porosity Fontainebleau sandstone sample. (b) The $4 \%$ porosity Fontainebleau sandstone sample. 
become lower than dry shear velocities. Note that the latter results were previously observed by King (1966), Nur and Simmons (1969), and Coyner (1984), among others, on many sandstones and other types of rocks.

\section{Low-frequency bulk modulus}

Experimental measurements of low-frequency bulk modulus are summarized in Figures 6 and 7, for the 13\% and 4\% porosity samples, respectively. For both sandstones, only measurements of axial strain $\varepsilon_{\mathrm{ax}}$ were used to calculate volumetric strain, $\varepsilon_{v}$ (i.e., $\varepsilon_{v}=3 \varepsilon_{\mathrm{ax}}$ ) because the radial strain data were of too poor quality to be quantitatively processed.

It was found that both sandstones exhibit linear elastic behavior during oscillation tests and that the obtained bulk modulus is independent of the oscillation amplitude (considering the error bars on measurements). This was not a priori guaranteed, remembering that the overall strain during oscillation tests lies in the range from $10^{-6}$

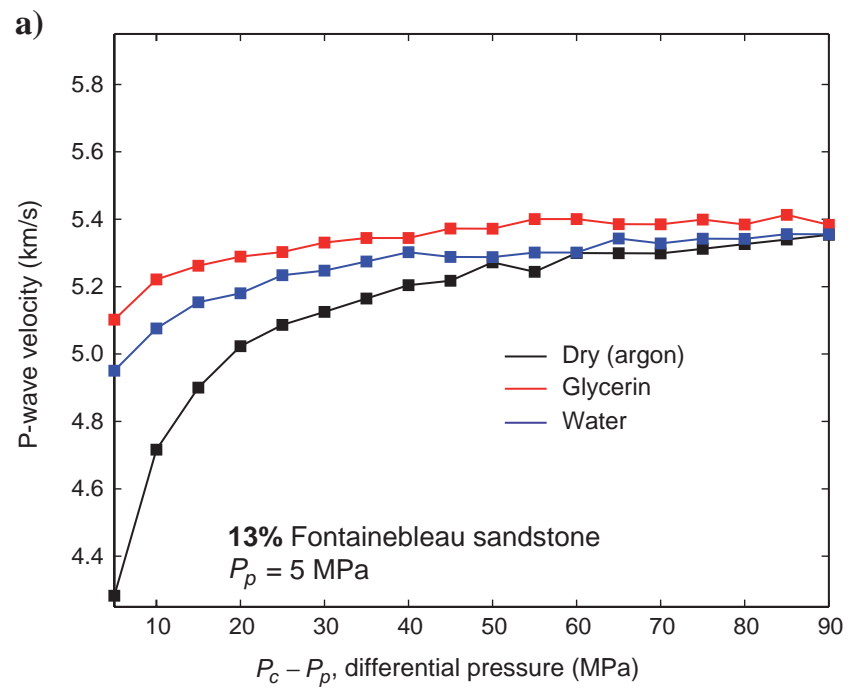

c)

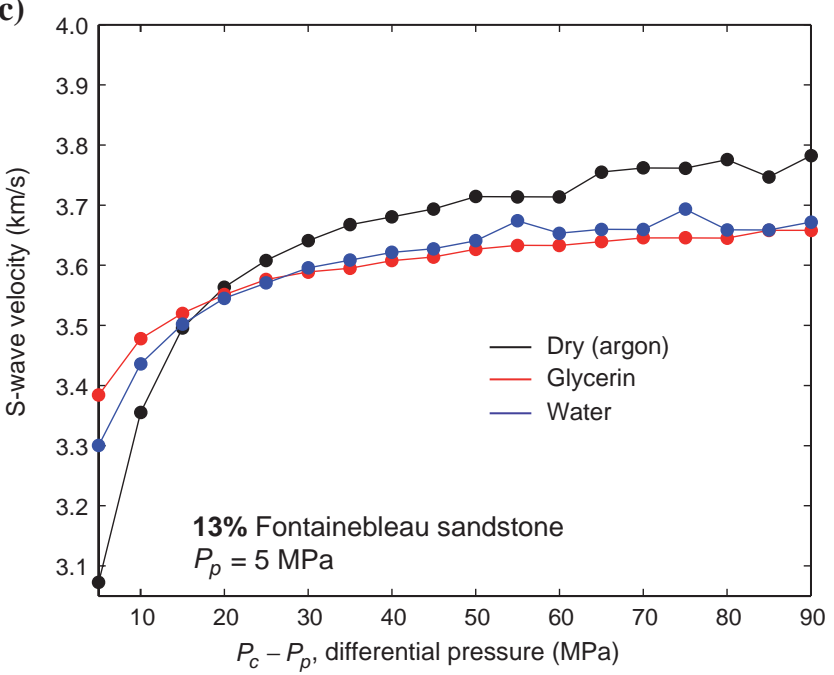

to $10^{-5}$. In addition, the systematic absence of phase shift between measured confining pressure and volumetric strain (or, equivalently, the absence of a hysteresis loop in the corresponding stress-strain curve), which was observed for the three pore fluid saturants and for both sandstones, shows that there is no attenuation in the lowfrequency range of the experiments.

For the $13 \%$ Fontainebleau sandstone, at each given hydrostatic pressure, the glycerin- and water-saturated low-frequency bulk moduli remain unchanged with frequency in the range of 0.02 to $0.1 \mathrm{~Hz}$ and equal to the low-frequency dry bulk modulus (Figure 6). Hence, the first conclusion that can be reached from such results is that the glycerin- and water-saturated $13 \%$ sample behaves as fully drained at the low frequencies that were used in the forced oscillation tests. This is confirmed by the good match between the low-frequency and dry ultrasonic bulk modulus, which was calculated from $\left(V_{\mathrm{P}}, V_{\mathrm{S}}\right)$, over the complete pressure range (Figure 8a). The same conclusions hold for the $4 \%$ Fontainebleau sandstone (Figures 7 and 9a), although the quality of the low-frequency data

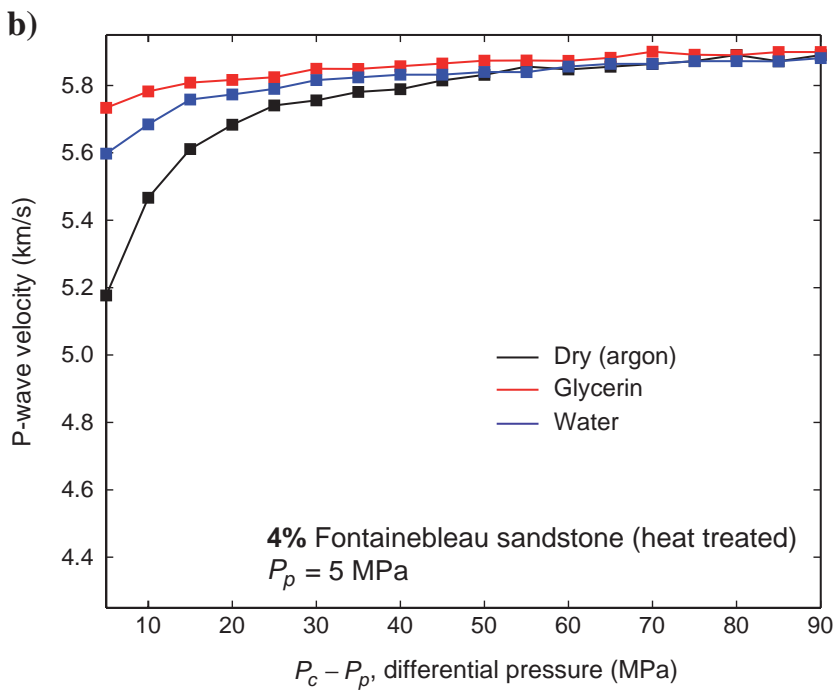

d)

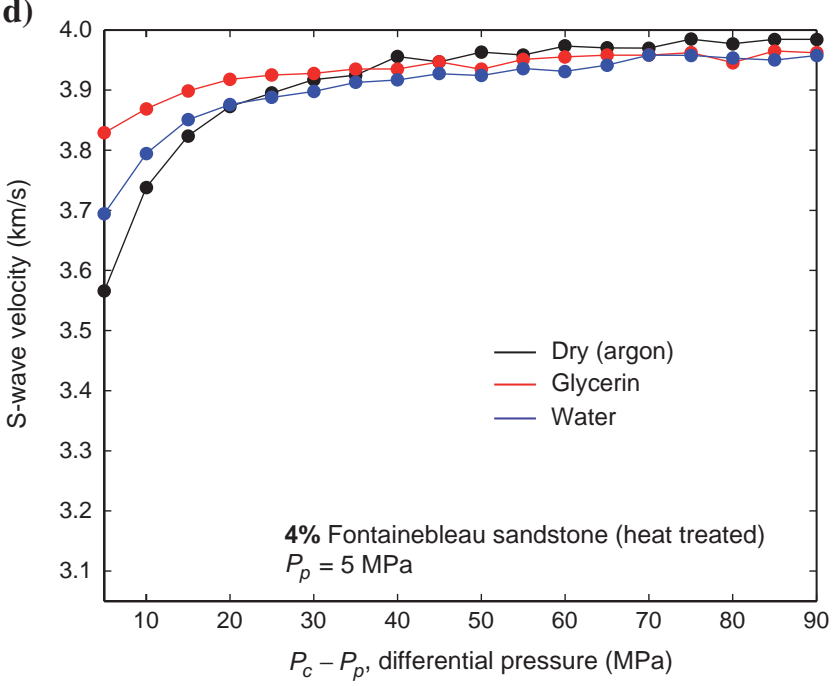

Figure 5. Ultrasonic velocity measurements for the dry, glycerin-saturated, and water-saturated Fontainebleau sandstone samples, as a function of $P_{c}-P_{p}$, differential pressure. (a) P-wave velocity, $13 \%$ porosity sample. (b) P-wave velocity, $4 \%$ porosity sample. (c) S-wave velocity, $13 \%$ porosity sample. (d) S-wave velocity, $4 \%$ porosity sample. 
is not as good as for the $13 \%$ sample. The large error bars are not surprising, because the $4 \%$ sample is stiffer than the $13 \%$ sample and because, at the small oscillation amplitudes used for lowfrequency tests, the limit of accuracy of the strain gauges is almost reached. Errors might also come from the quality of the gluing of the strain gauges.

\section{DISCUSSION}

\section{Ultrasonic velocity data}

The dependence of ultrasonic P- and S-wave velocities on the compressibility of the pore fluid can be interpreted in light of the micromechanics of cracked porous rocks. At ultrasonic frequen-

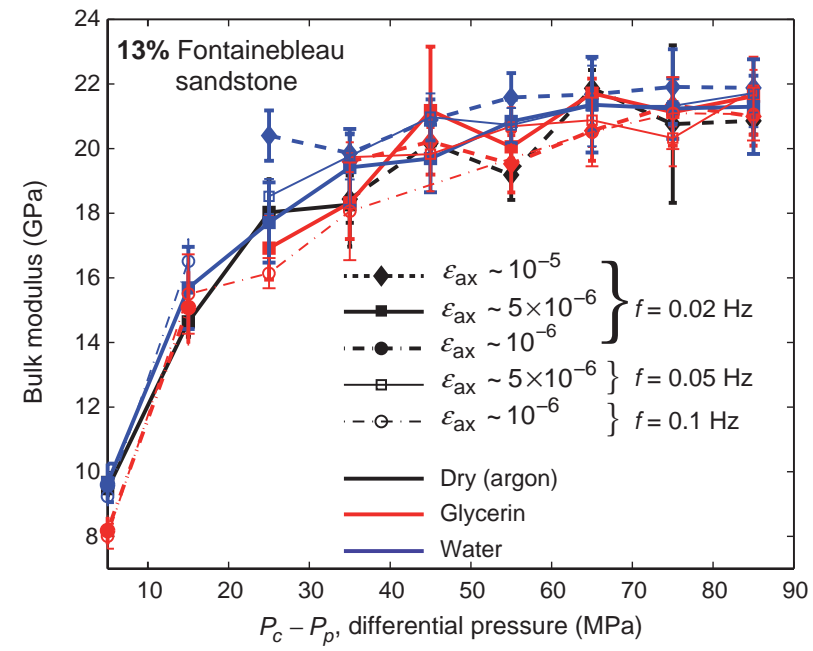

Figure 6. Bulk modulus measurements at low frequency, using oscillations of confining pressure (at different amplitudes), for the $13 \%$ porosity Fontainebleau sandstone (dry, glycerin-saturated, and water-saturated).

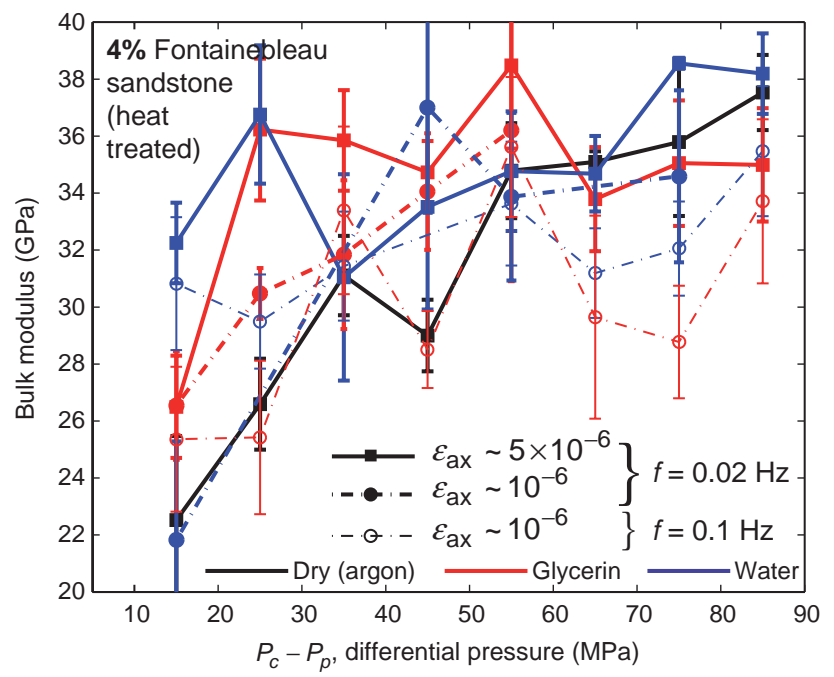

Figure 7. Bulk modulus measurements at low frequency, using oscillations of confining pressure (at different amplitudes), for the 4\% porosity Fontainebleau sandstone (dry, glycerin-saturated, and water-saturated). cies, it is realistic to assume that the fluid is trapped in each pore. It is also recalled that $V_{\mathrm{P}}=\sqrt{[K+(4 / 3) G] / \rho}$ and $V_{\mathrm{S}}=\sqrt{G / \rho}$, where $(K, G)$ are the bulk and shear moduli and $\rho$ is the rock density. At low pressures (properly speaking, at low differential pressures), a significant population of open cracks, having small aspect ratio, is present. The compressibility of such fluid-saturated cracks is nearly equal to the compressibility of the pore fluid. Because closable cracks represent a very small porosity, the overall effective bulk modulus of a rock containing saturated thin cracks is, to a good approximation, equal to the bulk modulus of the surrounding solid containing the cracks (Budiansky and O'Connell, 1976; Henyey and Pomphrey, 1982), which is here formed by the high-pressure matrix containing the saturated equant pores. Such analysis explains the very weak pressure dependence of saturated $V_{\mathrm{P}}$. The shear compliance of saturated thin cracks depends on the fluid compressibility because externally applied shear stresses can result in resolved compressive stresses on cracks having particular orientations (Shafiro and Kachanov, 1997; David, 2012). This "stiffening effect" in saturated cracks during the passing of a shear wave is significant: for the $13 \%$ sandstone, the saturated shear modulus measured on the glycerin-saturated sample is $30 \%$ higher than the dry shear modulus, at the smallest differential pressure (5 MPa) (Figure 5c). Such a stiffening effect overcomes the effect of the fluid density because saturated $V_{\mathrm{S}}$ is still higher than dry $V_{\mathrm{S}}$ by $10 \%$. On the contrary, the shear compliance of equant pores is almost insensitive to the fluid compressibility (Suvorov and Selvadurai, 2011; David, 2012). This explains why saturated $V_{\mathrm{S}}$ becomes lower than dry $V_{\mathrm{S}}$ at high pressures. In other words, the presence of this "crossover point" between dry and saturated shear velocities, at intermediate pressures, corresponds to the point at which the acoustic signature becomes mostly controlled by the non-closable pores.

The Gassmann model, which assumes that the saturated shear modulus is equal to the dry shear modulus, would predict that the saturated $V_{\mathrm{S}}$ is always lower than the dry $V_{\mathrm{S}}$ because of the effect of fluid density. The predictions of the Gassmann equation for the undrained bulk modulus (see equation 1) also lie well below the ultrasonic saturated bulk modulus (cf. Figures $8 b$ and $9 b$ ). It is therefore clear from these experimental measurements that, except at high pressures, the Gassmann model is not valid at ultrasonic frequencies for this particular rock.

\section{Low-frequency bulk modulus}

Another purpose of Figures 8 (13\% sample) and 9 (4\% sample) is to compare the saturated low-frequency bulk modulus (n.b., data taken at $f=0.02 \mathrm{~Hz}$ are only shown for clarity), to the saturated ultrasonic bulk modulus, which can equivalently be referred to as the saturated high-frequency bulk modulus. The saturated low-frequency bulk modulus has previously been shown to be the drained bulk modulus because it matches both low-frequency and ultrasonic dry data (Figures $8 \mathrm{a}$ and 9a). The second main implication of the experimental measurements of the saturated bulk modulus is that a significant difference is clearly observed between the drained and the high-frequency saturated bulk moduli. Such moduli represent, respectively, the most compliant and stiffest values of the frequencydependent elastic behavior. At low pressure $\left(P_{c}-P_{p}=5 \mathrm{MPa}\right)$, the saturated bulk modulus increases, between low and high frequencies, by approximately $80 \%$ and $40 \%$ for the $13 \%$ and $4 \%$ samples, respectively (glycerin- and water-saturated). In contrast, at high pressure $\left(P_{c}-P_{p}=85 \mathrm{MPa}\right)$, the increase of the bulk modulus 
with frequency is only $15 \%$ and $5 \%$, respectively. As for the analysis previously carried for the ultrasonic measurements, it is therefore clear that the frequency dependence of the saturated elastic moduli is highly controlled by pore structure, and more precisely by the presence of thin cracks. The experimental results show that velocity dispersion is much greater in a porous rock containing a mixture of pore shapes (e.g., equant pores and open flat cracks at low pressures) than in a porous rock containing pores of relatively similar shapes (e.g., nonclosable pores at high pressures) (Endres and Knight, 1997; Adelinet et al., 2011).

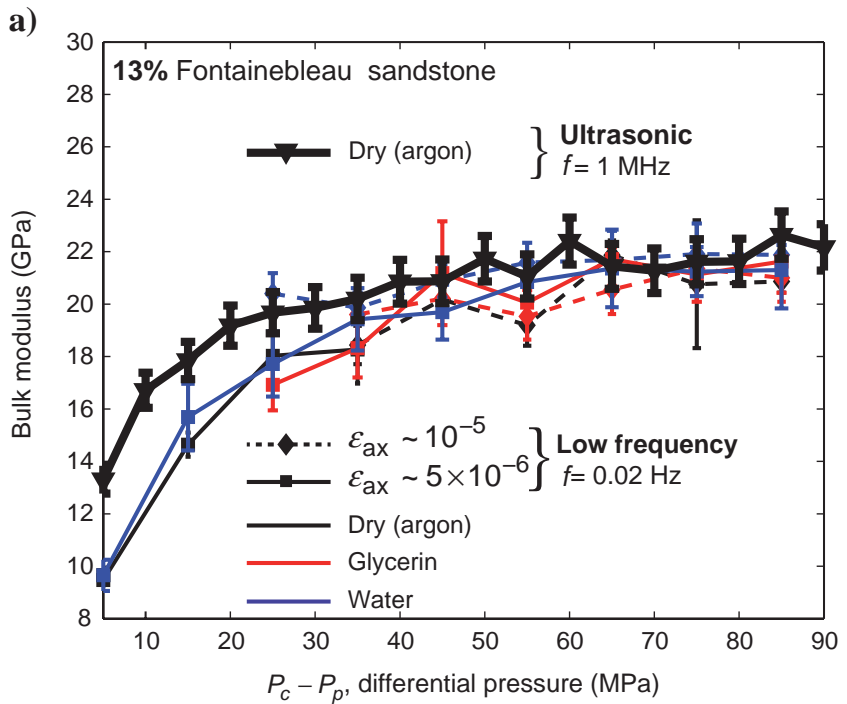

The undrained bulk modulus, according to Gassmann (1951), is

$$
K_{u}=\frac{\phi\left(\frac{1}{K_{0}}-\frac{1}{K_{f}}\right)+\left(\frac{1}{K_{0}}-\frac{1}{K_{d}}\right)}{\frac{\phi}{K_{d}}\left(\frac{1}{K_{0}}-\frac{1}{K_{f}}\right)+\frac{1}{K_{0}}\left(\frac{1}{K_{0}}-\frac{1}{K_{d}}\right)},
$$

where $\phi$ is the porosity, $K_{0}$ is the bulk modulus of the minerals, $K_{f}$ is the bulk modulus of the pore fluid, and $K_{d}$ is the drained (or,

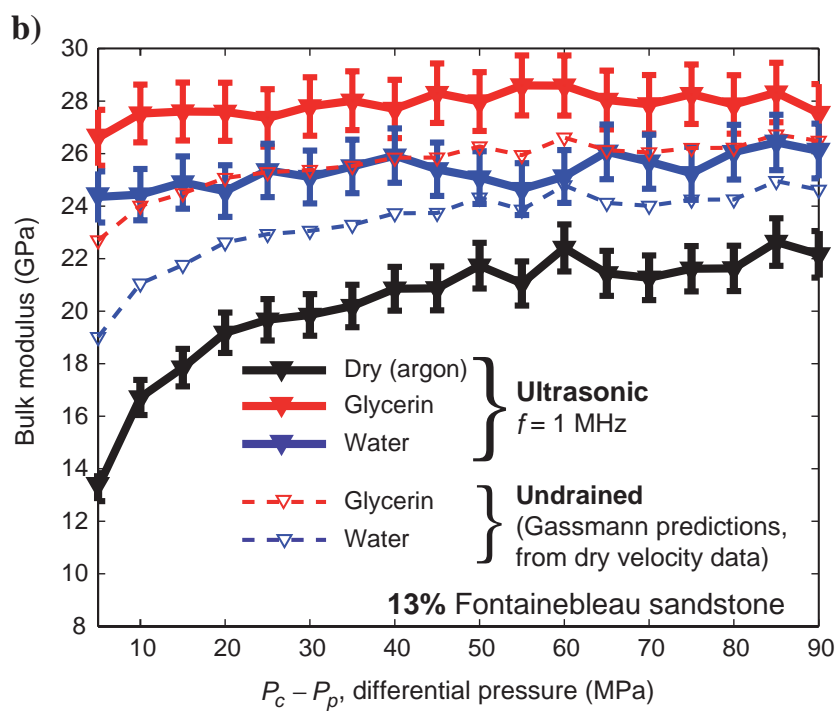

Figure 8. (a) Low-frequency bulk modulus at frequency $f=0.02 \mathrm{~Hz}$ (see Figure 6), compared with dry bulk modulus obtained from ultrasonic data (b). (b) Experimental results for bulk modulus at ultrasonic frequency (1 MHz), calculated from P-and S-wave ultrasonic velocity measurements. Predictions for the undrained bulk modulus, as expected from Gassmann's model (equation 1), are also shown. Data for the $13 \%$ porosity Fontainebleau sandstone.

a)

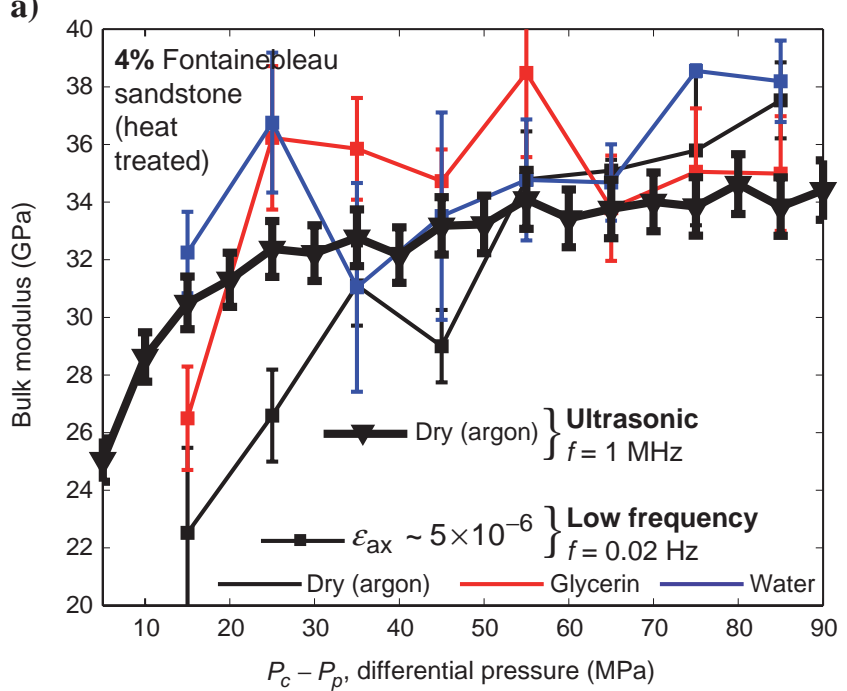

b)

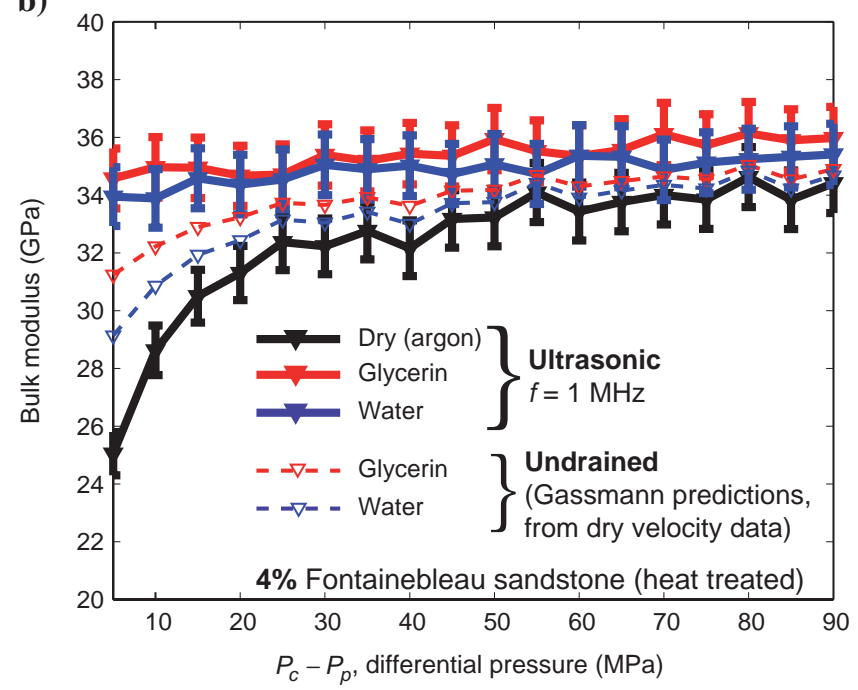

Figure 9. (a) Low-frequency bulk modulus at frequency $f=0.02 \mathrm{~Hz}$ (see Figure 7), compared with dry bulk modulus obtained from ultrasonic data (b). (b) Experimental results for bulk modulus at ultrasonic frequency (1 MHz), calculated from P-and S-wave ultrasonic velocity measurements. Predictions for the undrained bulk modulus, as expected from Gassmann's model (equation 1), are also shown. Data for the 4\% porosity Fontainebleau sandstone. 
equivalently, dry) bulk modulus. Predictions for the undrained bulk modulus were obtained using dry velocity data for $K_{d}$, experimental values for $\phi$, the data of Table 2 for $K_{f}$, and $K_{0}=37 \mathrm{GPa}$ for quartz (Mavko et al., 2009). As expected, the predicted undrained bulk modulus values lie between the drained and high-frequency saturated measurements, for the $13 \%$ and $4 \%$ porosity samples, glycerin- and water-saturated (Figures $8 \mathrm{~b}$ and 9b). The difference between undrained elastic behavior, in which local pore pressure equilibrium is assumed, and high-frequency elastic behavior, in which each pore behaves as if it was "isolated" with regards to fluid flow, is interpreted as the resulting effect of local fluid flow or "squirt-flow" between the most compliant pores to the nearby less compliant pores. The amount of such dispersion is, again, much higher at low pressures in the presence of open cracks. At the smallest differential pressure ( $5 \mathrm{MPa}$ ), the difference between the Gassmann and the high-frequency bulk moduli is almost $30 \%$ and $20 \%$ for the $13 \%$ porosity sample (glycerin- and water-saturated, respectively), and around $15 \%$ for the $4 \%$ porosity sample, for both pore fluids. Such values are in the same range as the ones that were previously measured by Adelinet et al. (2010) on an $8 \%$ porosity basalt, dry and water saturated. Another important result of Figures $8 \mathrm{~b}$ and $9 \mathrm{~b}$ is that dispersion becomes negligible at high pressures. Indeed, the rock then contains only non-closable "equant" pores, which, to the first order, have similar shapes. Under bulk compression, the Gassmann assumption of local pore pressure equilibrium is thus respected, regardless of whether these pores are isolated, as at high frequencies, or not. It is therefore expected that the undrained bulk moduli, as predicted from the Gassmann equation, and the high-frequency saturated bulk moduli, measured by ultrasonic frequencies, will become closer at high pressures. Similar observations are made by King and Marsden (2002) and by David (2012) on other sandstones. They are consistent with the results of Rasolofosaon and Zinszner (2012).

The lower frequency bound for which Gassmann's predictions for undrained velocities can be considered to be valid can be roughly estimated, remembering that drained behavior occurs if sufficient time is allowed for the achievement of pore pressure equilibrium (by global fluid diffusion) over a region of characteristic dimension $l$. An estimation of the critical frequency $f_{u}$ between drained and undrained regimes is (Cleary, 1978)

$$
f_{u}=\frac{k}{\phi \eta C_{f} l^{2}},
$$

where $C_{f}=1 / K_{f}$ is the fluid compressibility. For the present laboratory experiments, using the data of Table 2 , the measured permeabilities, and taking the characteristic length to be the rock sample diameter, or length $(l=4 \mathrm{~cm})$, it is found, for the $13 \%$ porosity sandstone, that the critical frequency below which drained behavior occurs is $f_{u} \sim 4 \mathrm{~Hz}$ (glycerin) and $f_{u} \sim 2 \mathrm{kHz}$ (water). This confirms that, during the oscillation tests $(0.02-0.1 \mathrm{~Hz})$, it was indeed the drained bulk modulus that was measured on this sample. For the $4 \%$ porosity sandstone, $f_{u} \sim 0.01 \mathrm{~Hz}$ (glycerin) and $f_{u} \sim 4 \mathrm{~Hz}$ (water). Thus, under glycerin saturation, the frequency of oscillations of confining pressure might be close to the limit of drained behavior; however, no significant deviation from the water-saturated bulk modulus (which is then confirmed to be the drained modulus) is observed (Figure 7). As low-frequency data for the $4 \%$ sample are subject to large error bars, additional experimental measurements of elastic moduli as a function of frequency would be needed.

\section{CONCLUSIONS}

New measurements of the bulk modulus at low frequency $(0.02$ to $0.1 \mathrm{~Hz}$ ) have been successfully obtained in the laboratory on two Fontainebleau sandstone samples, over the differential pressure range 5-95 $\mathrm{MPa}$, in conjunction with ultrasonic velocities and static measurements, using three different pore fluids. Over the frequency range $0.02-01 \mathrm{~Hz}$, the $13 \%$ and $4 \%$ porosity samples behave as fully drained under glycerin and water saturations. This result is confirmed when comparing this frequency range to the limiting frequency for drained behavior that can be estimated from permeability measurements. The velocity dispersion between low and high frequencies that is observed for both samples, water and glycerin saturated, is significant at low differential pressures when cracks are open. The predictions of the Gassmann model for the undrained $\mathrm{P}$ - and S-wave velocities, in the low- to intermediate-frequency regime, lie well below the ultrasonic measurements. The difference between the Gassmann and high-frequency moduli is, again, much more significant at low pressures - approximately $20 \%$ for the two samples.

More laboratory measurements of wave velocities are needed over a much wider frequency range (and notably at intermediate frequencies) before raising the hope of constraining a model for frequency dependence. Attempts to measure Young's modulus and Poisson's ratio over the seismic range $(0.001$ to $300 \mathrm{~Hz})$ on the two Fontainebleau sandstones tested here are reported in David (2012). Promising preliminary results have been obtained by Jackson et al. (2011), and Tisato and Madonna (2012), among others. Such measurements of elastic properties as well as attenuation factors over large frequency ranges are crucial to clearly demarcate the very low frequency drained regime, the low to intermediate frequency Gassmann regime, and the isolated high frequency regime. The transition frequencies demarcating these regimes, which can only be roughly estimated by oversimplified theoretical models, must be characterized by strong attenuation of velocities. Unfortunately, no clear experimental evidence of the existence of three distinct regimes of frequency behavior has been given so far. One could equivalently imagine a smooth variation of wave velocities between the drained and high-frequency regime, with a single peak of attenuation, with the Gassmann type of elastic behavior corresponding only to an intermediate regime of elastic behavior, but not properly to a plateau.

\section{ACKNOWLEDGMENTS}

The authors wish to thank Y. Pinquier for technical support during the experiments as well as C. David, J.-C. Colombier, and J. Wasserman for the mercury porosimetry and triple-weighting porosimetry measurements.

\section{REFERENCES}

Adam, L., and M. Batzle, 2008, Elastic properties of carbonates from laboratory measurements at seismic and ultrasonic frequencies: The Leading Edge, 27, 1026-1032, doi: 10.1190/1.2967556.

Adam, L., M. Batzle, and I. Brevik, 2006, Gassmann fluid substitution and shear modulus variability in carbonates at laboratory seismic and 
ultrasonic frequencies: Geophysics, 71, no. 6, F173-F183, doi: 10.1190/1 .2358494 .

Adelinet, M., J. Fortin, and Y. Guéguen, 2011, Dispersion of elastic moduli in a porous-cracked rock: Theoretical predictions for squirt flow: Tectonophysics, 503, 173-181, doi: 10.1016/j.tecto.2010.10.012.

Adelinet, M., J. Fortin, Y. Guéguen, A. Schubnel, and L. Geoffroy, 2010, Frequency and fluid effects on elastic properties of basalt: Experimental investigations: Geophysical Research Letters, 37, L02303, doi: 10.1029/ 2009GL041660.

Batzle, M., D.-H. Han, and R. Hofmann, 2006, Fluid mobility and frequency-dependent seismic velocity — Direct measurements: Geophysics, 71, no. 1, N1-N9, doi: 10.1190/1.2159053.

Batzle, M., R. Hofmann, D.-H. Han, and J. Castagna, 2001, Fluids and frequency dependent seismic velocity of rocks: The Leading Edge, 20, 168-171, doi: 10.1190/1.1438900.

Bourbié, T., O. Coussy, and B. Zinszner, 1987, Acoustics of porous media: Editions Technip.

Bourbié, T., and B. Zinszner, 1985, Hydraulic and acoustic properties as a function of porosity in Fontainebleau sandstone: Journal of Geophysical Research, 90, 11524-11532, doi: 10.1029/JB090iB13p11524.

Brantut, N., A. Schubnel, and Y. Guéguen, 2011, Damage and rupture dynamics at the brittle ductile transition: The case of gypsum: Journal of Geophysical Research, 116, B01404, doi: 10.1029/2010JB007675.

Budiansky, B., and R. J. O'Connell, 1976, Elastic moduli of a cracked solid: International Journal of Solids and Structures, 12, 81-97, doi: 10.1016/ 0020-7683(76)90044-5.

Cleary, M. P., 1978, Elastic and dynamic response regimes of fluidimpregnated solids with diverse microstructures: International Journal of Solids and Structures, 14, 795-819, doi: 10.1016/0020-7683(78) 90072-0.

Coyner, K. B., 1984, Effect of stress, pore pressure, and pore fluids on bulk strain, velocity, and permeability of rocks: Ph.D. thesis, Massachusetts Institute of Technology.

Darot, M., Y. Guéguen, and M. L. Baratin, 1992, Permeability of thermically cracked granite: Geophysical Research Letters, 19, 869-872, doi: 10 1029/92GL00579.

Dautriat, J., N. Gland, J. Guelard, A. Dimanov, and J. L. Raphanel, 2009 Axial and radial permeability evolutions of compressed sandstones: End effects and shear-band induced permeability anisotropy: Pure and Applied Geophysics, 166, 1037-1061, doi: 10.1007/s00024-009-0495-0.

David, C., M. Darot, and D. Jeannette, 1993, Pore structures and transport properties of sandstone: Transport in Porous Media, 11, 161-177, doi: 10 1007/BF01059632.

David, E. C., 2012, The effect of stress, pore fluid and pore structure and elastic wave velocities in sandstones: Ph.D. thesis, Imperial College London.

David, E. C., N. Brantut, A. Schubnel, and R. W. Zimmerman, 2012, Sliding crack model for nonlinearity and hysteresis in the uniaxial stress-strain curve of rock: International Journal of Rock Mechanics and Mining Sciences, 52, 9-17, doi: 10.1016/j.ijrmms.2012.02.001.

David, E. C., and R. W. Zimmerman, 2012, Pore structure model for elastic wave velocities in fluid-saturated sandstones: Journal of Geophysical Research, 117, B07210, doi: 10.1029/2012JB009195.

Dullien, F. A. L., 1992, Porous media: Fluid transport and pore structure, 2nd ed.: Academic Press.

Dvorkin, J., G. Mavko, and A. Nur, 1995, Squirt flow in fully saturated rocks: Geophysics, 60, 97-107, doi: 10.1190/1.1443767.

Endres, A. L., and R. J. Knight, 1997, Incorporating pore geometry and fluid pressure communication into modeling the elastic behavior of porous rocks: Geophysics, 62, 106-117, doi: 10.1190/1.1444110.

Fortin, J., Y. Guéguen, and A. Schubnel, 2007, Effect of pore collapse and grain crushing on ultrasonic velocities and $V_{\mathrm{p}} / V_{\mathrm{s}}$ : Journal of Geophysical Research, 112, B08207, doi: 10.1029/2005JB004005.

Fortin, J., A. Schubnel, and Y. Guéguen, 2005, Elastic wave velocities and permeability evolution during compaction of Bleurswiller sandstone: International Journal of Rock Mechanics and Mining Sciences, 42, 873-889, doi: 10.1016/j.ijrmms.2005.05.002.

Fredrich, J. T., K. H. Greaves, and J. W. Martin, 1993, Pore geometry and transport properties of Fontainebleau sandstone: International Journal of Rock Mechanics and Mining Sciences, 30, 691-697, doi: 10.1016/01489062(93)90007-Z.

Gassmann, F., 1951, Uber die Elasticität Poröser Medien (On the elasticity of porous media): Vierteljahrsschrift der Naturforschenden Gesellschaft in Zürich, 96, 1-23.

Henyey, F. S., and N. Pomphrey, 1982, Self-consistent elastic moduli of a cracked solid: Geophysical Research Letters, 9, 903-906, doi: 10.1029/ GL009i008p00903.
Jackson, I., and M. S. Paterson, 1987, Shear modulus and internal friction of calcite rocks at seismic frequencies: Pressure, frequency and grain size dependence: Physics of the Earth and Planetary Interiors, 45, 349-367, doi: 10.1016/0031-9201(87)90042-2.

Jackson, I., H. Schijns, D. R. Schmitt, J. Mu, and A. Delmenico, 2011, A versatile facility for laboratory studies of viscoelastic and poroelastic behaviour of rocks: Review of Scientific Instruments, 82, 064501, doi: 10.1063/1.3592154.

Jones, T. D., and A. Nur, 1983, Velocity and attenuation in sandstone at elevated temperatures and pressures: Geophysical Research Letters, 10, 140-143, doi: 10.1029/GL010i002p00140.

King, M. S., 1966, Wave velocities in rocks as a function of changes in overburden pressure and pore fluid saturants: Geophysics, 31, 50-73, doi: 10 $.1190 / 1.1439763$.

King, M. S., and J. R. Marsden, 2002, Velocity dispersion between ultrasonic and seismic frequencies in brine-saturated reservoir sandstones: Geophysics, 67, 254-258, doi: 10.1190/1.1451700.

Landolt, H., and R. Börnstein, 1982, High-pressure properties of matter, vol. 4: Springer.

Lenormand, R., 2003, Interpretation of mercury injection curves to derive pore size distribution: Presented at the International Symposium of the Society of Core Analysts.

Mavko, G., T. Mukerji, and J. Dvorkin, 2009, The rock physics handbook: Cambridge University Press.

Murphy, W. F., 1982, Effects of partial water saturation on attenuation in Massilon sandstone and Vycor porous glass: Journal of the Acoustical Society of America, 71, 1458-1468, doi: 10.1121/1.387843.

Nur, A., and W. F. Murphy, 1981, Wave velocities and attenuation in porous media with fluids: Proceedings of the 4th International Conference on Continuum Models of Discrete Systems, 311-327.

Nur, A., and G. Simmons, 1969, The effect of saturation on velocity in low porosity rocks: Earth and Planetary Science Letters, 7, 183-193, doi: 10 1016/0012-821X(69)90035-1.

O'Connell, R. J., and B. Budiansky, 1977, Viscoelastic properties of fluidsaturated cracked solids: Journal of Geophysical Research, 82, 57195735, doi: 10.1029/JB082i036p05719.

Ougier-Simonin, A., J. Fortin, Y. Guéguen, A. Schubnel, and F. Bouyer, 2011, Cracks in glass under triaxial conditions: International Journal of Engineering Science, 49, 105-121, doi: 10.1016/j.ijengsci.2010.06 .026 .

Rasolofosaon, P. N. J., and B. Zinszner, 2012, Experimental verification of the petroelastic model in the laboratory - Fluid substitution and pressure effects: Oil and Gas Science and Technology, 67, 303-318, doi: 10.2516/ ogst/2011167.

Sams, M. S., J. P. Neep, M. H. Worthington, and M. S. King, 1997, The measurement of velocity dispersion and frequency-dependent intrinsic attenuation in sedimentary rocks: Geophysics, 62, 1456-1464, doi: 10 $.1190 / 1.1444249$.

Shafiro, B., and M. Kachanov, 1997, Materials with fluid-filled pores of various shapes: Effective elastic properties and fluid pressure polarization: International Journal of Solids and Structures, 34, 3517-3540, doi: 10 .1016/S0020-7683(96)00185-0.

Song, I., and J. Renner, 2008, Hydromechanical properties of Fontainebleau sandstone: Experimental determination and micromechanical modeling: Journal of Geophysical Research, 113, B09211, doi: 10.1029/ 2007JB005055.

Spencer, J. W., 1981, Stress relaxations at low frequencies in fluid-saturated rocks: Attenuation and modulus dispersion: Journal of Geophysical Research, 86, 1803-1812, doi: 10.1029/JB086iB03p01803.

Suvorov, A. P., and A. P. S. Selvadurai, 2011, Effective medium methods and a computational approach for estimating geomaterial properties of porous materials with randomly oriented ellipsoidal pores: Computers and Geotechnics, 38, 721-730, doi: 10.1016/j.compgeo.2011.04.002.

Tisato, N., and C. Madonna, 2012, Attenuation at low seismic frequencies in partially saturated rocks: Measurements and description of a new apparatus: Journal of Applied Geophysics, 86, 44-53, doi: 10.1016/j.jappgeo 2012.07.008.

Winkler, K., 1986, Estimates of velocity dispersion between seismic and ultrasonic frequencies: Geophysics, 51, 183-189, doi: 10.1190/1 .1442031.

Winkler, K., A. Nur, and M. Gladwin, 1979, Friction and seismic attenuation in rocks: Nature, 277, 528-531, doi: 10.1038/277528a0.

Zimmerman, R. W., W. H. Somerton, and M. S. King, 1986, Compressibility of porous rocks: Journal of Geophysical Research, 91, 12765-12777, doi: 10.1029/JB091iB12p12765. 